\title{
Metformin Treatment: A Potential Cause of Megaloblastic Anemia in Patients with Type 2 Diabetes Mellitus
}

This article was published in the following Dove Press journal: Diabetes, Metabolic Syndrome and Obesity: Targets and Therapy

\author{
Oana Albai ${ }^{1,2}$ \\ Bogdan Timar $\mathbb{D}^{2,3}$ \\ Diana Loreta Paun ${ }^{4}$ \\ Alexandra Sima (iD) ${ }^{1,2}$ \\ Deiana Roman $\mathbb{D}^{1,2}$ \\ Romulus Timar ${ }^{1,2}$ \\ 'Second Department of Internal \\ Medicine, "Victor Babes" University of \\ Medicine and Pharmacy, Timisoara, \\ Romania; ${ }^{2}$ Department of Diabetes and \\ Metabolic Diseases, "Pius Brinzeu" \\ Emergency Hospital, Timisoara, Romania; \\ ${ }^{3}$ Department of Functional Sciences, \\ "Victor Babes" University of Medicine \\ and Pharmacy, Timisoara, Romania; \\ ${ }^{4}$ Department of Public Health, Associate \\ Professor in the Department of \\ Endocrinology, "Carol Davila" University \\ of Medicine and Pharmacy, Bucuresti, \\ Romania
}

Introduction: Vitamin B12 (cobalamin) deficiency is a frequent cause of megaloblastic anemia, manifested through various symptoms. Screening for this deficiency can be justified in case of patients with one or more risk factors present from the following: gastric resections, inflammatory bowel disease, use of metformin over a prolonged period of time, administration of proton pump inhibitors or $\mathrm{H} 2$ histamine receptor blockers for more than 12 months and in case of adults over 75 years of age. One method of determining vitamin B12 deficiency is measuring its serum levels, as well as performing measurements of serum levels of methylmalonic acid and homocysteine levels, which experience an increase in the early stages of vitamin B12 deficiency.

Clinical Case: We bring to your attention, the case of a 62 years old patient diagnosed with Type 2 Diabetes Mellitus in 2015 that presented in the emergency room in October 2019 with an altered general condition, nausea, vomiting, abdominal pain, palpitation, and dyspnea. Treatment with metformin was initiated from the diagnosis of Type 2 Diabetes Mellitus, four years before. Investigations established the diagnosis of megaloblastic anemia by vitamin B12 deficiency. The symptoms disappeared after the injection of vitamin B12.

Conclusion: Periodical dosing of vitamin B12 should be performed in the case of patients with Type 2 Diabetes Mellitus treated with metformin, especially if they associate anemia and/or peripheral diabetic polyneuropathy.

Keywords: megaloblastic anemia, metformin, vitamin B12 deficiency

\section{Introduction}

Diabetes Mellitus (DM) is a chronic, non-communicable disease accompanied by severe complications and increased costs, being the seventh mortality cause worldwide. According to the World Health Organization (WHO), one in eleven adults is diagnosed with DM, 436 million cases being currently registered, with the estimated number for 2045 rising to 700 million cases. Unfortunately, it is estimated that one in two people with DM remains undiagnosed, amounting to approximately 232 million cases worldwide.

Metformin represents the first-line drug intervention recommended for Type 2 Diabetes Mellitus patients by all international guidelines, if not otherwise contraindicated. Alongside lifestyle changes, metformin is indicated from the very diagnosis of the disease. This drug has proven its efficacy along the years, as well as its safety and tolerability. Due to its complex action mechanisms metformin is also prescribed in other diseases such as Polycystic Ovary Syndrome (PCOS). ${ }^{2,3}$
Correspondence: Bogdan Timar

"Victor Babes" University of Medicine and Pharmacy, 2 Eftimie Murgu, Timisoara

30004I, Romania

Tel +4074I528093

Email timar.bogdan@umft.ro 
Although pharmacotherapy for Type 2 Diabetes Mellitus is very complex and heterogenous, according to all guides and protocols, most are used as second-line drugs, associated with or after initiation of metformin. All this makes metformin to remain a widely used drug worldwide in the future. In 2017, metformin was the fourth largest drug prescribed in the United States, with over 78 million prescriptions. $^{4}$

Its main action mechanism is represented by the reduction of hyperglycemia through decreasing the hepatic production of glucose, decreasing the intestinal absorption of glucose, as well as increasing insulin sensitivity, having proven beneficial effects on both basal and postprandial glycemia. ${ }^{5}$ In the liver, metformin reduces gluconeogenesis through the stimulation of AMPK (AMP-activated protein kinase) due to the increase of cytosolic AMP levels. In the muscle tissue, it increases the activity of muscular AMPK and the movement of GLUT-4 receptors towards the cellular membrane. By counteracting glucose toxicity and lipid toxicity Metformin leads to the preservation of $\beta$ cells and restores insulin secretion, consequently reducing glycemic values without increasing insulinemia, making its risk of hypoglycemic events minimal. ${ }^{6}$

The mechanisms through which metformin contributes to weight loss can be explained by the reduction of intestinal absorption of carbohydrates, its effect on lowering insulin resistance, reducing leptin and ghrelin levels after glucose administration and by inducing the lipolytic and anorexic effect of GLP-1 activation. Metformin is a molecule that does not have hypoglycemia or weight gain as side effects. ${ }^{7,8}$

Metformin has a favorable action on cardiovascular risk factors: it decreases the risk of a myocardial infarction or stroke and lowers DM-related mortality. ${ }^{9}$

Although determination of vitamin B12 serum levels is not routinely performed, it should be performed periodically for patients under long-standing treatment with metformin. $^{10}$

Vitamin B12, also known as cobalamin, is an essential nutrient, mainly to DNA and erythrocyte formation and contributes to the optimal functioning of the nervous system. It can be found in animal products (meat, fish, eggs, dairy products), fortified products such as cereal and some types of bread as well as in soy or nutritional yeast. ${ }^{11,12}$

Cobalamin is released from food-binding proteins by pepsin and gastric acid in the stomach, consecutively binding to haptocorrin. In the duodenum, cobalamin is released under the action of pancreatic proteases and binds to the intrinsic factor (IF) produced by gastric parietal cells. The IF-B12 complex is endocytosed in ileal cells through the cubam receptor, then it is divided and cobalamin is bound to transcobalamin (synthesized in the liver). This complex leaves the ileal cells and enters the circulation a few hours after ingestion. ${ }^{13}$

Vitamin B12 deficiency can cause a wide range of symptoms that affect patient's mental and physical health. The presence of anemia is accompanied by general signs and symptoms: irritability, fatigue, dyspnea, skin pallor, palpitations. Also, digestive disorders are present and consist of atrophy of the digestive mucosa: tongue (Hunter's glossitis), stomach and intestines. In addition, histamineresistant achlorhydria occurs and there is an increased incidence of gastric cancer. Neurological disorders by affecting the nervous system are represented by peripheral nerve lesions, with demyelination and axonal degeneration; spinal cord injuries. It is found to affect the thermal and vibrational sensitivity, paresthesia, ataxia, diminishing or even abolishing the osteotendinous reflexes and positivizing the Babinski sign. In addition, neuropsychiatric disorders also occur: irritability, difficulty concentrating, depression. ${ }^{13}$

These symptoms can appear slowly and worsen over time if not treated quickly and correctly.

\section{Clinical Case}

A 62 years old patient arrived at the Centre for Diabetes, Nutrition and Metabolic Diseases presenting with fatigability, headache, dizziness, dyspnea during moderate effort, palpitations, nausea, bloating and epigastric pain and in the right hypochondrium. We mention that no other neurological signs have been described. Given the symptoms, it was decided to admit the patient in the Diabetes, Nutrition and Metabolic Diseases Clinic for further investigations and establishing the correct course of treatment.

The patient included in the study signed the informed consent for the acquisition, analysis, and publishing of the anonymized data collected. Since no personal identification data were used in this manuscript, the ethics committee approval is not needed.

It needs to be mentioned that the patient had been diagnosed with Type 2 Diabetes Mellitus in 2015 and was undergoing treatment with metformin $1 \mathrm{~g}$ twice a day and sitagliptin $100 \mathrm{mg}$ once a day. Metformin treatment had been initiated at the time of diagnosis (2015), and sitagliptin had been added to the therapeutic plan in 
2018. The patient had been presenting for evaluation visits every three months since being diagnosed with Type 2 Diabetes Mellitus.

Also, the patient was receiving treatment with $\beta$ blocker (Bisoprolol $5 \mathrm{mg}$ /day), ACE inhibitor (Perindopril $10 \mathrm{mg} /$ day) as well as a thiazide diuretic (Indapamide $1.5 \mathrm{mg} /$ day).

The patients' history did not reveal alcohol abuse or smoking, the physical exam revealed obesity grade II $(\mathrm{BMI}=37 \mathrm{~kg} / \mathrm{m} 2)$ and an abdominal circumference (AC) of $116 \mathrm{~cm}$, skin paleness and slight dehydration, rhythmic heartbeat, blood pressure of $105 / 70 \mathrm{mmHg}$, a pulse of 92 $\mathrm{b} / \mathrm{min}$, no pathological heart murmurs and a glycaemia equal to $220 \mathrm{mg} / \mathrm{dl}$.

Blood tests revealed an unsatisfactory glycemic control, quantified by an HbAlc of $9.8 \%$ as well as a low HDLc level of $29 \mathrm{mg} / \mathrm{dl}$, while renal function and hepatic function were normal.

The blood panel presented severe modifications prompting more detailed investigations in order to determine the cause of the anemia: $\mathrm{Hb}=8.7 \mathrm{~g} / \mathrm{dl}, \mathrm{Ht}=29 \%, \mathrm{H}=$ $2.3 \times 106 / \mu \mathrm{L}, \mathrm{L}=5.9 \times 103 / \mu \mathrm{L}, \mathrm{T}=191 \times 103 / \mu \mathrm{L}, \mathrm{MEV}=$ $119.6 \mathrm{fl}, \mathrm{MEH}=39 \mathrm{pg}, \mathrm{MECH}=34 \mathrm{~g} / \mathrm{dl}$. Iron levels were normal $77 \mathrm{microg} / \mathrm{dl}$ (normal values being between 50 and $170 \mu / \mathrm{dl})$.

According to WHO, anemia is defined by a $\mathrm{Hb}$ level under $13 \mathrm{~g} / \mathrm{dl}$ in men and under $12 \mathrm{~g} / \mathrm{dl}$ in women. If the mean volume of erythrocytes is greater than $100 \mathrm{fl}$, one could consider macrocytic anemia, the most common form encountered being megaloblastic anemia.

Given the hematologic panel, a peripheral blood smear was performed, and it identified anisocytosis with hypochromic erythrocytes, macrocytes, codocytes, isolated thrombocytes as well as thrombocytes in small or medium groups.

Considering the poor glycemic control, as well as high glycemic values and clinical symptoms, treatment with oral antidiabetics drugs was stopped, and insulin therapy was initiated in a basal-bolus regimen, with dosages adjusted according to glycemic values. Consecutive to treatment modification, it was noticed that the patients' symptoms had significantly improved, dyspnea and gastric discomfort were disappeared. An EKG, chest X-ray, abdominal echography and gastroscopy were performed. These investigations did not reveal any notable pathological changes, significant to other conditions. Vitamin B12 and folate were measured. Results showed that the concentration of B12 was very low: 113 pmol/1 (normal values are between 191 and $663 \mathrm{pmol} / \mathrm{l}$ for the European population) and serum concentration of folate was in normal range: $18.6 \mathrm{ng} / \mathrm{mL}$ (normal values are between 4.6 and $34.8 \mathrm{ng} / \mathrm{mL}$ ).

Substitution treatment with vitamin B12 was initiated in the form of intramuscular injection, initially with 1000 $\mu \mathrm{g} /$ week, over the first 2 months, consecutively the dosage being reduced to $1000 \mu \mathrm{g}$ every 2 weeks.

For obtaining a good glycemic control, the administration of a long-acting insulin analogue (Glargine) once daily (at bedtime) in association with sitagliptin $100 \mathrm{mg} /$ day (in the morning) was the preferred option.

After 3 months the patient was re-admitted in the Diabetes Clinic for re-evaluation: Table 1 presents the main biological parameters investigated at the time of diagnosis as well as 3 months after substitution treatment.

Glycemic control was significantly improved, having a decrease of $\mathrm{HbAlc}$ of $1.6 \mathrm{pp}$ (from $9.8 \%$ to $8.2 \%$ ) (Table 2).

\section{Discussion}

The fragility of erythrocytes in patients with DM is multifactorial and includes various insufficiencies, some autoimmune diseases, the aggravation of pre-existing factors, various drug classes and hormonal disruptions.

Although vitamin B12 is available through a healthy diet, its deficit is relatively frequent, especially in people over 50 years old and in those following a vegetarian or vegan diet. It is possible at times that the intake of vitamin B12 be sufficient and the problem to be present in its processing, determining what is referred to as functional deficit of vitamin B12. ${ }^{14}$

Among the most common causes of vitamin B12 deficit, we encounter: 1) pernicious anemia: an autoimmune condition when gastric cells that produce a protein called intrinsic factor, essential in the absorption of vitamin B12, are effected; 2) diseases of the stomach and small intestine which can determine an inadequate absorption of Vitamin B12: atrophic gastritis, $H$. pylori infection, intestinal parasitosis, Crohn's disease, celiac disease, surgical interventions; 3) drugs: proton pump inhibitors (when used over a prolonged period of time for gastritis or ulcer), metformin (used in DM), anticonvulsants, methotrexate, colchicine, etc.; 4) inadequate intake: vegan or vegetarian diets; 5) pregnancy and lactation. ${ }^{15,16}$

In most cases, administration of vitamin B12 shots or tablets is sufficient to treat this condition. ${ }^{17}$ 
Table I The Main Biological Parameters at Time of Admittance and After Three Months of Substitution Treatment with Vitamin BI2

\begin{tabular}{|c|c|c|c|}
\hline Parameters & $\begin{array}{l}\text { Initially (at } \\
\text { Diagnosis) }\end{array}$ & $\begin{array}{l}\text { After } 3 \text { Months of Substitution Treatment } \\
\text { with Vit B I } 2\end{array}$ & $\begin{array}{l}\text { Normal } \\
\text { Values }\end{array}$ \\
\hline $\mathrm{Hb}(\mathrm{g} / \mathrm{dl})$ & 8.7 & 13,8 & $11.5-15$ \\
\hline $\mathrm{Ht}(\%)$ & 29 & 37 & $35-46$ \\
\hline Erythrocyte $\left(\times 10^{3} / \mu \mathrm{L}\right)$ & 2.3 & 4.4 & $4-5.5$ \\
\hline Leucocytes $\left(\times 10^{6} / \mu \mathrm{L}\right)$ & 5.9 & 5.6 & $4-9.5$ \\
\hline Thrombocytes $\left(\times 10^{3} / \mu \mathrm{L}\right)$ & 191 & 211 & $150-400$ \\
\hline Mean Erythrocyte Volume (MEV) (fl) & 119.6 & 86.3 & 79-98 \\
\hline Mean Erythrocyte Hemoglobin (MEH) (pg) & 34 & 30.1 & $27-32$ \\
\hline $\begin{array}{l}\text { Mean Erythrocyte Hemoglobin Concentration } \\
(\mathrm{MECH})(\mathrm{g} / \mathrm{dl})\end{array}$ & 39 & 34 & $32-36$ \\
\hline Erythrocyte Sedimentation Rate $(\mathrm{ESR})(\mathrm{mm} / \mathrm{lh})$ & 28 & 17 & $2-20$ \\
\hline Vitamin B I2 (pmol/l) & 113 & 433 & $191-663$ \\
\hline Folate $(\mathrm{ng} / \mathrm{mL})$ & 18.6 & 21 & $4.6-34.8$ \\
\hline Syderemia $(\mu / \mathrm{dl})$ & 77 & 88 & $50-170$ \\
\hline AST (U/L) & 29 & 27 & $15-37$ \\
\hline ALT (U/L) & 45 & 39 & $14-59$ \\
\hline Alkaline Phosphatase (FAL) (U/L) & 58 & 54 & $46-116$ \\
\hline Total Bilirubin (TB) $(\mathrm{mg} / \mathrm{dl})$ & 0.657 & 0.584 & $0.2-1$ \\
\hline $\operatorname{Urea}(\mathrm{mg} / \mathrm{dl})$ & 40 & 30 & $15-39$ \\
\hline Creatinine $(\mathrm{mg} / \mathrm{dl})$ & 0.8 & 0.77 & $0.55-1.02$ \\
\hline GFR (mL/min) & 79 & 83 & $>60$ \\
\hline $\mathrm{HbAIc}(\%)$ & 9.8 & 8.2 & $<7$ \\
\hline
\end{tabular}

A study concerning megaloblastic anemia with a follow-up period of 11.8 years showed that $9 \%$ of patients treated with metformin presented symptoms of the disease. ${ }^{18}$

Although there are not very many reported cases in the literature, form the beginning of the 1980s' Callaghan et al reported the first case of megaloblastic anemia as a consequence of prolonged use of metformin, without being able to demonstrate the exact causality relation between them. ${ }^{19}$ In this case, treatment with vitamin B12 determined the increase of $\mathrm{Hb}$ levels, as well as a decrease in MEV.

Liu et al presented two similar cases that developed anemia, cognitive decline, peripheral neuropathy, along with degeneration of the spinal cord. ${ }^{20}$
One case of megaloblastic anemia due to a vitamin B12 deficiency was described by Fujita et al. In this case, the patient had total gastrectomy (at age of 60) because had stomach cancer. This 67 years old woman, which had Type 2 Diabetes Mellitus, developed megaloblastic anemia due to vitamin B12 deficiency precipitated by the introduction of metformin therapy. ${ }^{21}$

Vitamin B12, folic acid and vitamin B6 are involved in the metabolism of homocysteine. Vitamin B12 deficiency causes hyperhomocysteinemia due to inadequate function of the methionine-synthetase enzyme. There is a significant body of evidence showing that vitamin B12 and folate supplements, with or without vitamin B6 lead to a decrease of homocysteine levels in people with cardiovascular disease and DM. ${ }^{22}$ One study in which men and 
Table 2 The Glycemic Profile at the Time of Admittance and After 3 Months of Undergoing the Revised Treatment Plan

\begin{tabular}{|l|l|l|l|l|l|l|l|l|l|l|}
\hline Treatment Plan/Glycemic Profile & h 07 & h II & h I3 & h I6 & h I9 & h 22 & h 03 & h 07 & $\begin{array}{l}\text { Glycemic Mean } \\
\text { (mg/dl) }\end{array}$ & $\begin{array}{l}\text { HbAlc } \\
\text { (\%) }\end{array}$ \\
\hline $\begin{array}{l}\text { Metformin cp I000 mg I-0-I + Sitagliptin cP } \\
\text { I00 mg I-0-0 } \\
\text { (at admittance) }\end{array}$ & 162 & 201 & 170 & 203 & 185 & 233 & 198 & 174 & 191 & 9.8 \\
\hline $\begin{array}{l}\text { Sitagliptin 100 mg I-0-0 + Glargine 22 UI } \\
\text { (22:00 h) } \\
\text { (after 3 months) }\end{array}$ & 120 & 157 & 131 & 179 & 142 & 138 & 137 & 133 & 142 & 8.2 \\
\hline
\end{tabular}

women took multivitamin supplements for 8 weeks presented a significant decrease of homocysteine levels. ${ }^{23}$ The Heart Outcomes Prevention Evaluation (HOPE) 2 trial, which included 5522 patients with ages over 54, cardiovascular disease or DM, that received daily treatment with $2.5 \mathrm{mg}$ folic acid, $50 \mathrm{mg}$ vitamin B6 and $1 \mathrm{mg}$ vitamin B12 for 5 years showed a decrease in homocysteine levels and stroke, but did not influence the risk for major cardiovascular events. ${ }^{24}$ In the Western Norway B Vitamin Intervention Trial, that included 3096 patients on which angio-coronarography was performed after which they received daily vitamin $\mathrm{B} 12(0.4 \mathrm{mg})$, folic acid $(0.8 \mathrm{mg})$ with or without vitamin B6 supplements for 1 year proved a decrease in homocysteine levels of $30 \%$, but did not affect overall mortality not the risk for major cardiovascular events over the 38-month follow-up period. ${ }^{25}$ Similar results have been encountered in the Norwegian Vitamin (NORVIT) trial and in the Vitamin Intervention for Stroke Prevention trial. $^{26,27}$

All these studies demonstrate the importance of vitamin B12, it is necessary for the health of nerve tissue, for the proper functioning of the brain and for the production of red blood cells.

Vitamin B12 deficiency can be avoided by optimizing lifestyle and by including more sources of vitamin B12 in the daily diet or by taking supplements.

\section{Conclusion}

When prescribing a drug, it is the physician's duty to consider the possible side effects and, at times, alert the patient regarding the most frequent ones, in order for them to be reported if present.

Metformin can cause megaloblastic anemia, due to vitamin B12 deficiency; therefore, we would advise annual blood panels to be required by the prescribing physician for all patients undergoing treatment with metformin. If abnormalities regarding red blood cells are found, further investigations should be performed, including serum folate levels.

\section{Disclosure}

The authors report no conflicts of interest in this work.

\section{References}

1. IDF. Diabetes atlas ninth edition; 2019. Available from: www.diabe tesatlas.org.

2. American Diabetes Association. Pharmacologic approaches to glycemic treatment: standards of medical care in diabetes-2018. Diabetes Care. 2018;41(Suppl 1):S73-S85. doi:10.2337/dc18-S008

3. Wang YW, He SJ, Feng X, et al. Metformin: a review of its potential indications. Drug Des Devel Ther. 2017;11:2421-2429. doi:10.2147/ DDDT.S141675

4. Metformin hydrochloride - drug usage statistics. ClinCalc; 2019. Accessed April 7, 2020.

5. Graham GG, Punt J, Arora M, et al. Clinical pharmacokinetics of metformin. Clin Pharmacokinet. 2011;50(2):81-98. doi:10.2165/ 11534750-000000000-00000

6. Foretz M, Guigas B, Bertrand L, Pollak M, Viollet B. Metformin: from mechanisms of action to therapies. Cell Metab. 2014;20 (6):953-966. doi:10.1016/j.cmet.2014.09.018

7. Graham Rena D, Hardie G, Pearson ER. The mechanisms of action of metformin. Diabetologia. 2017;60(9):1577-1585. doi:10.1007/ s00125-017-4342-z

8. Valencia WM, Palacio A, Tamariz L, Florez H. Metformin and ageing: improving ageing outcomes beyond glycaemic control. Diabetologia. 2017;60(9):1630-1638. doi:10.1007/s00125-0174349-5

9. Eurich DT, Majumdar SR, McAlister FA, Tsuyuki RT, Johnson JA. Improved clinical outcomes associated with metformin in patients with diabetes and heart failure. Diabetes Care. 2005;28 (10):2345-2351. doi:10.2337/diacare.28.10.2345

10. Ting RZ, Szeto CC, Chan MH, Ma KK, Chow KM. Risk factors of vitamin B(12) deficiency in patients receiving metformin. Arch Intern Med. 2006;166(18):1975-1979. doi:10.1001/archinte.166.18.1975

11. U.S. Department of Agriculture. Agricultural Research Service. FoodData Central; 2019.

12. Institute of Medicine. Food and Nutrition Board. Dietary Reference Intakes: Thiamin, Riboflavin, Niacin, Vitamin B6, Folate, Vitamin B12, Pantothenic Acid, Biotin, and Choline. Washington, DC: National Academy Press; 1998.

13. Banerjee R, Ragsdale SW. The many faces of vitamin B 12: catalysis by cobalamin-dependent enzymes. Annu Rev Biochem. 2003;72 (1):209-247. doi:10.1146/annurev.biochem.72.121801.161828

14. Kaferle J, Strzoda CE. Evaluation of macrocytosis. Am Fam Physician. 2009;79(3):203-208. 
15. Aroda VR, Edelstein SL, Goldberg RB, et al. Long-term metformin use and vitamin B12 deficiency in the diabetes prevention program outcomes study. J Clin Endocrinol Metab. 2016;101:1754-1761.

16. Bell DS. Metformin-induced vitamin B12 deficiency presenting as a peripheral neuropathy. South Med J. 2010;103(3):265-267. doi:10.1097/SMJ.0b013e3181ce0e4d

17. Carmel R. How I treat cobalamin (vitamin B12) deficiency. Blood. 2008;112(6):2214-2221. doi:10.1182/blood-2008-03-040253

18. Filioussi K, Bonvoas S, Katsaros T. Should we screen diabetes patients using biguanides for megaloblastic anaemia? Aust Fam Physician. 2003;32(5):383-384.

19. Callaghan TS, Hadden DR, Tomkin GH. Megaloblastic anaemia due to vitamin B12 malabsorption associated with long-term metformin treatment. $\mathrm{Br}$ Med J. 1980;280(6225):1214-1215. doi:10.1136/ bmj.280.6225.1214

20. Liu KW, Dai LK, Jean W. Metformin-related vitamin B12 deficiency. Age Ageing. 2006;35(2):200-201. doi:10.1093/ageing/afj042

21. Fujita H, Narita T, Yoshioka N, et al. A case of megaloblastic anemia due to vitamin B12 deficiency precipitated in a totally gastrectomized type II diabetic patient following the introduction of metformin therapy. Endocr J. 2003;50(4):483-484. doi:10.1507/endocrj.50.483

22. Toole JF, Malinow MR, Chambless LE, et al. Lowering homocysteine in patients with ischemic stroke to prevent recurrent stroke, myocardial infarction, and death: the vitamin intervention for stroke prevention (VISP) randomized controlled trial. JAMA. 2004;291 (5):565-575. doi:10.1001/jama.291.5.565
23. McKay DL, Perrone G, Rasmussen H, Dallal G, Blumberg JB. Multivitamin/mineral supplementation improves plasma B-vitamin status and homocysteine concentration in healthy older adults consuming a folate-fortified diet. J Nutr. 2000;130(12):3090-3096. doi:10.1093/jn/130.12.3090

24. Gustavo Saposnik JG, Ray PS, McQueen M, McQueen M, Lonn E. The HOPE 2 investigators. Homocysteine-lowering therapy and stroke risk, severity, and disability. Stroke. 2009;40(4):1365-1372. doi:10.1161/STROKEAHA.108.529503

25. Ebbing M, Bleie Ø, Ueland PM, et al. Mortality and cardiovascular events in patients treated with homocysteine-lowering $\mathrm{B}$ vitamins after coronary angiography: a randomized controlled trial. JAMA. 2008;300(7):795-804. doi:10.1001/jama.300.7.795

26. Bønaa KH, Njølstad I, Ueland PM, et al. NORVIT trial investigators. Homocysteine lowering and cardiovascular events after acute myocardial infarction. $N$ Engl $J$ Med. 2006;354(15):1578-1588. doi:10.1056/NEJMoa055227

27. Spence JD, Bang H, Chambless LE, Stampfer MJ. Vitamin intervention for stroke prevention trial: an efficacy analysis. Stroke. 2005;36 (11):2404-2409. doi:10.1161/01.STR.0000185929.38534.f3

\section{Publish your work in this journal}

Diabetes, Metabolic Syndrome and Obesity: Targets and Therapy is an international, peer-reviewed open-access journal committed to the rapid publication of the latest laboratory and clinical findings in the fields of diabetes, metabolic syndrome and obesity research. Original research, review, case reports, hypothesis formation, expert opinion and commentaries are all considered for publication. The manuscript management system is completely online and includes a very quick and fair peer-review system, which is all easy to use. Visit http://www.dovepress.com/testimonials.php to read real quotes from published authors. 